\title{
Undergraduate group projects: Challenges and learning experiences
}

Teaching Support Centre, École Polytechnique Fédérale de Lausanne, Switzerland

^Email: siara.isaac@epfl.ch http://dx.doi.org/

10.5339/qproc.2015.elc2014.19

(C) 2015 Isaac, Tormey, licensee Bloomsbury Qatar Foundation Journals. This is an open access article distributed under the terms of the Creative Commons Attribution license CC BY 4.0, which permits unrestricted use,

distribution and reproduction in any medium, provided the original work is properly cited.
Siara Isaac*, Roland Tormey

\section{ABSTRACT}

Working in groups and managing projects are important professional skills for engineers, and there is a growing demand to teach and assess such skills. But what should be taught and when? Tuckman's famous "stages of development of performing groups" provides a framework for understanding the types of challenges which groups face. Yet, as with any abstract model, it will not be transferred into students' practice if they do not see it as relevant to their lived experiences.

In 2014, a new course exploring the nexus of social and engineering issues in relation to the global challenges facing humanity was added to the obligatory program for all first year engineering students. Among the many noble goals of this course, in addition to gaining a more nuanced view of the global challenges from both an engineering and social science perspective, are the development of transversal skills such as team work, communication, presentation, library research and ethical engagement.

The taught material about team work was presented online, allowing for the use learning analytics on students' online responses to assess how well the "stages of group formation" literature matched students' experiences. It also allowed us to consider how students' perceptions of the challenges they will face differed from challenges they actually did face, as well as the implications of this for how they should be taught about group processes. 


\section{LITERATURE REVIEW}

Over the last forty years there has been a significant development in the understanding of the role of teams in workplaces and it is widely accepted that engineering students need to learn to use a range of interpersonal skills including the ability to work as part of teams ${ }^{1}$. Consequently it is no surprise that the US criteria for accreditation of engineering programmes require that students demonstrate "an ability to function on multidisciplinary teams" and "an ability to communicate effectively" ${ }^{2}$. Similar criteria are present in many accreditation processes, including France and francophone Switzerland ${ }^{3}$.

Working in a group is not always an immediately rewarding experience for engineering students. Colbeck et al., for example found some students struggled with questions of leadership, dealing with free-riders or "slackers", and dealing with conflicts and with the egos of group members ${ }^{4}$. It has been suggested that such challenges can become very problematic for students, and Ford and Morice claiming that for "students already struggling with the pressures of university life in general, the added burden of trying to work within a seemingly dysfunctional team was often the "last straw."' approach is that students simply learn from their personal experience of group work - positive and negative. It can be argued that experience is not a perfect teacher, and the evidence collected by Colbeck et al. led them to conclude, that without "faculty guidance, it seemed that only a few student teams developed positive goal or role interdependence" 4,5 . More generally, Cohen has argued that "it is a great mistake to assume that [learners] ... know how to work with each other in a constructive collegial fashion... [and, therefore] Students must be prepared for cooperation"6. This is perhaps more important when high school systems and competitive selection procedures have prioritised and rewarded individualism and competition over collectivism and collaboration.

What sort of content on group process is appropriate in an introductory course that accompanies engineering students' first forays into group work? It seems sensible to suggest giving students a set of intellectual tools to understand what was happening in their group - a set of thinking tools that would allow them to reflect upon, make sense of and decide how to act, in the case of conflicts and challenges. Social psychology has provided a number of different theoretical accounts which attempt to make sense of the process of working in small groups. Forsyth ${ }^{7}$ lists a range of possible ways of making sense of group processes including Tuckman's stages of group development, Bales' equilibrium model, and Gersick's punctuated equilibrium model. Of these, the most influential model ${ }^{8}$ is that proposed by Bruce Tuckman ${ }^{9}$ which is commonly known as the "forming, storming, norming and performing" model of group development. Tuckman's model has been described as 'the most predominantly referred to and most widely recognized in organizational literature ${ }^{10}$. The success of the model probably owes something to the pedagogical value of the simple and easily memorable names which he ascribes to each of the four stages. At the same time, the model is felt by researchers in the field to have a scientific utility, and one of his articles ${ }^{11}$ has now been cited by almost 2,000 published papers. While more recent formulations for describing group process development exist, some of the most influential (such as Wheelan's Integrated Model of Group Development ${ }^{12}$ ), are in fact closely based on Tuckman's earlier work.

Given its prominence in the field, its status as the model first introduced in group dynamics texts (see Forsyth, 2010 for example), its pedagogically friendly formulation, and given that what is being described is no more than an introductory course, to seems reasonable to suggest that Tuckman's model would be a good starting point for students looking to understand their own experience of the development of a group.

However, there are two issues worth considering. The first is the question of timeframe. Student projects typically take place within a single semester with between 12 and 15 weeks available for such projects. But Wheelan, Davidson and Tilin ${ }^{13}$ studying groups that met for between one and 15 months, found that groups which had been meeting for shorter periods of time tended to be at stages one and two of Tuckman's model. Members of groups which had been meeting for shorter periods were also less likely to describe their group in terms of productive work. It may be, then, that groups which are formed for student projects will be too short to allow students to experience all of the stages of group development described by Tuckman. In such a case, the model provided to students may not appear to match their experience of groups and so may appear unrealistic to them.

A second issue to consider here is students' prior experiences of group work. Even if the project group meets for too short a period to allow students to experience the different stages of group development, students who have prior experience of groups may be able to draw on their prior experiences in order to understand the utility of a model of group development. Colbeck et al. found 
that engineering students with less prior experience of workplace or academic group work are perhaps more likely to experience difficulties in establishing cohesive groups ${ }^{4}$. Those with few prior experiences may not have the empirical data with which to understand how groups work, and how a theoretical model like Tuckman's can be used to make sense of them.

In summary, the last few decades have seen a growing emphasis on early experience of group projects as part of engineering education programmes ${ }^{1,4,14}$. The literature suggests these should be accompanied by education on group processes (as well as on project management skills, both oral and written communication skills, and accessing and using information). However, in order to be able to see course content on group process as being useful, students should see it is addressing their needs and concerns in groups. It may be that limited prior experience and short project timeframe may make this difficult. This raises a number of questions regarding students' learning about group processes as part of a first-year course which includes a group project element. Before beginning the project, what are students' beliefs about the likely problems or challenges they will encounter in the group? Do these change once they actually have some experience of working on the group project? How do students self-assess their group in terms of the stages of group development? These questions are important for understanding how to best teach group development to first year engineering students. They are the questions that this study seeks to address.

\section{METHOLODOLGY}

This study uses a descriptive methodology on students' responses to questions about the challenges and benefits of working in groups on projects in a required, first-year course at the engineering school, Ecole Polytechnique Fédérale de Lausanne (EPFL) in Switzerland. The course, Enjeux mondiaux (Global Issues), was offered for the first time in the spring of 2014 and attended by some 1,700 first year students from across the 13 engineering and science disciplines offered by the school. The group work skills were taught in the online component of the course via video lectures and on-line exercises, quizzes and questionnaires. This was equivalent to roughly 12 hours of student work. Students' responses to questions addressing the challenges of working in groups were in the context of the online modules, and were designed to encourage them to think about and develop specific skills for working in groups.

Participants: The majority of students entering first year are Swiss (roughly $65 \%$ ), $30 \%$ are French and the remaining $5 \%$ come from across the world. The average age of first year students is $17-18$ years. Overall, $27 \%$ percent of students are female but their distribution across the various engineering disciplines is unequal.

Instruments: This analysis grew out of our attempt to understand the appropriateness of the online resources for group development. It is important to note that these activities were designed to stimulate students' thinking about group work and not to test specific hypotheses or to generate ideal data for post-hoc analysis. Three sources of data were used.

- First, an open forum in the first week of the semester asked students to respond to the question "What behaviours in a team bother you the most?"

- Second, a quiz from week 6 concluded with questions which asked students to rank the importance of 5 aspects, on a 4 point likert scale, in terms of the source of conflict in their groups (Table 1). The 5 questions appeared to students in a random order.

- Finally, a self-reflective questionnaire developed by D.R. Clark ${ }^{15}$ about the frequency of different behaviours within their group was proposed to students between week 6 and the end of the term. The 2 final questions asked students to identify which stage of Tuckman's group development model their group was currently experiencing and the number of group meetings that had been held.

Instructional components: Students were assigned to one of 11 different classes which addressed different themes but which shared the same structure and assessment. Students received face-to-face lectures for first eight weeks of the term, followed by five weeks which were dedicated to project work with self-selected groups of five students. The students began forming their project group and planning their project during the first eight weeks, and then submitted short weekly progress reports. Final projects were submitted as posters and were also presented before a jury of including both the instructors and outside experts. The on-line content was assessed by written exam which counted for $10 \%$ of their final grade. 
Table 1. Questions inquiring about sources of tension in the group (Week 6).

\begin{tabular}{ll}
\hline $\begin{array}{l}\text { With a view to analysing the functioning of your group, } \\
\text { identify the impact of the following differences on your group work: }\end{array}$ & Response options \\
\hline $\begin{array}{l}\text { Our personality differences, or different styles of communication, } \\
\text { are a source of tension. }\end{array}$ & Absent in our group \\
$\begin{array}{l}\text { Our different grade aspirations or degrees of involvement } \\
\text { in the project are a source of tension. }\end{array}$ & Weak impact \\
$\begin{array}{l}\text { Our cultural or linguistics differences are a source of tension. } \\
\text { Our different disciplines are a source of tension. }\end{array}$ & Intermediate impact \\
Other elements, not listed, are a source of tension. & Important impact \\
\hline
\end{tabular}

In parallel to the face-to-face lectures, students had 6 weekly on-line lectures and exercises in preparation for their projects. These resources addressed working in groups, project design, and managing and citing relevant research resources. Effort was made to make the resources relevant to the project. The resources for working in groups, the focus on this paper, were based on Tuckman's stages and provided strategies for generating ideas and making decisions as a group, conflict resolution, and active listening.

Data collection and analysis: The purpose of this study was to explore students' concerns about group work, the difficulties they actually encountered over the semester, and to reflect on how to provide resources which appear more relevant to their experiences. It was not conceived of as a research project designed to test particular hypotheses. Rather it represents an attempt by some of those involved in the course to use existing data to better understand students' perspective in order to improve the quality of resources provided to students.

\section{RESULTS}

In total, some 1660 students visited the online resources at least once.

Week 1 data: In the first week of the term, students were asked to respond on an open forum to the question "What behaviours in a team bother you the most?" (Quels sont les comportements au sein d'un groupe qui vous gênent le plus?), resulting in 280 comments, including 122 which addressed more than one issue. Content analysis identified 17 categories of responses which were then grouped into 2 overarching categories: (a) interpersonal issues and (b) task-related issues, primarily based on whether the comment identified the issue as being a problem in terms of the impact on group members or on the advancement or quality of the project (Table 2). Comments from teaching assistants or questions about logistics were omitted (23). Task-related issues were cited most often (276 times) and also contained the most common concerns: that some group members were not concerned about producing high quality work (62 times) and that some members showed a lack of punctuality with respect to meetings and deadlines (57). This is consistent with the prior findings of Colbeck et al. ${ }^{4}$, who found that "free riders" and leadership were common concerns for students. Interpersonal issues were mentioned only about half as often (144 times), with dominating behaviour and lack of communication topping the list (51 and 49 times, respectively).

Week 6 data: Starting in week 6 , students responded to a questionnaire whose main goal was to allow them to test their comprehension of the concepts presented in that week's video about contributing productively to group work and resolving conflicts. The final part of the questionnaire asked them to rank the relative important of 5 different sources of conflict in their groups (Table 1; personality/communication, grade/commitment, culture/language, discipline, other). Overall, 1326 responses to these final questions were obtained. It seems likely that these responses can be taken as representative of the population, as the main objective of the quiz was relevant to all students and not just those experiencing tensions.

Four-fifths (81\%) of respondents reported having at least one source of tension which was having an intermediate or important impact in their group (1079 respondents) and 58\% reported at least one source of tension which was having an important impact (Table 3). Finally, only $5 \%$ of respondents reported having no sources of tension in their group, with a further $14 \%$ reporting that tensions had only a weak impact. 
Table 2. Initial frustrations with group work (Week 1).

\begin{tabular}{lcc}
\hline & \% of comments & Count \\
\hline Interpersonal issues, including & $\mathbf{5 2}$ & $\mathbf{1 4 4}$ \\
Individuals who impose/seek to dominate & 18 & 51 \\
Lack of communication & 18 & 49 \\
Bad group dynamics & 7 & 20 \\
Rudeness & 6 & 16 \\
Creating stress & 2 & 5 \\
Excluding one person & 1 & 3 \\
Task-related, including & $\mathbf{1 0 0}$ & $\mathbf{2 7 6}$ \\
Lack of concern for producing good work & 22 & 62 \\
Lack of punctuality & 21 & 57 \\
Requiring others to do your work & 18 & 49 \\
Lack of respect for group goals & 17 & 47 \\
Unconstructive critiques & 5 & 15 \\
Unproductive behaviour & 5 & 14 \\
Lack of organisation & 3 & 9 \\
Poor quality work & 3 & 8 \\
Lack of different perspectives & 2 & 6 \\
Digressing, day dreaming & 2 & 5 \\
Not having a leader & 1 & 4 \\
\hline
\end{tabular}

Table 3. Tensions within the group as reported by individuals.

\begin{tabular}{lcc}
\hline $\mathbf{N}=\mathbf{1 3 2 6}$ & \% of responses & Count \\
\hline At least one source of tension, with at least a weak impact & $95 \%$ & 1259 \\
At least one source of tension with at least an intermediate impact & $81 \%$ & 1074 \\
At least one source of tension with an important impact & $58 \%$ & 774 \\
\hline
\end{tabular}

Differences in personality or communication styles were both the most common and most severe types of tension, experienced in some degree by $88 \%$ of individuals and as an important source of tension by $38 \%$ (Figure 1). Differences in grade aspiration and level of involvement in the project, also identified by students in week 1 , were experienced in some degree by $82 \%$ of individuals and strongly $21 \%$. Challenges resulting from culture, language or disciplinary differences were not identified by any student in the initial forum, but were reported by $63 \%$ and $59 \%$ of respondents, respectively in the week 6 questionnaire.

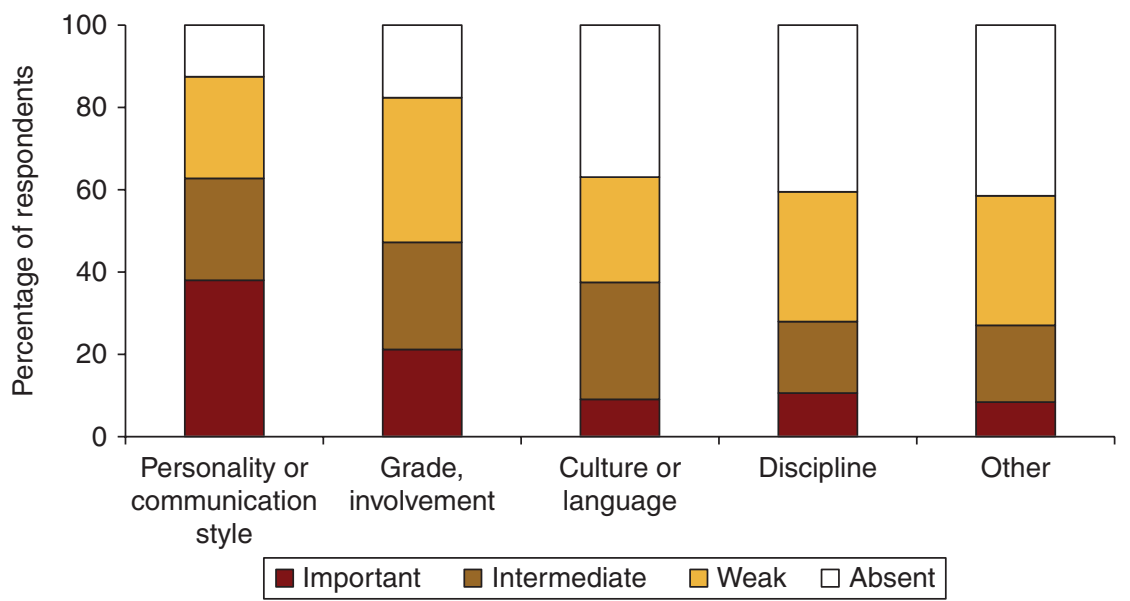

Figure 1. Sources and severity of group tension reported by students.

Later data: Between week 6 and the end of term, students were invited to complete a self-reflective questionnaire about the frequency of different types of behaviour in their group. A summary of their responses and a description of the different stages of group development was then emailed to them. "We try to achieve harmony by avoiding conflict." is a typical question. In general, students reported very little 'Storming' behavior - at least as it was operationalized in this questionnaire. However, the 
final questions of this questionnaire asked them to identify the stage they thought the group was currently experiencing and also the number of team meetings that had been held (Figure 2). 'Forming' declined chronologically and 'Performing' increased, however 'Norming' and 'Storming' remained quite present throughout. $80 \%$ of answers were obtained from individuals who had between 1 and 3 group meetings, and 'Norming' and 'Storming' are the stages most commonly reported, with 34\% and 36\% respectively (the fact that students identified themselves as being in a Storming stage without identifying 'Storming' behaviours could be interpreted as suggesting that the questions in Clark' ${ }^{15}$ questionnaire may not be culturally appropriate for this group).
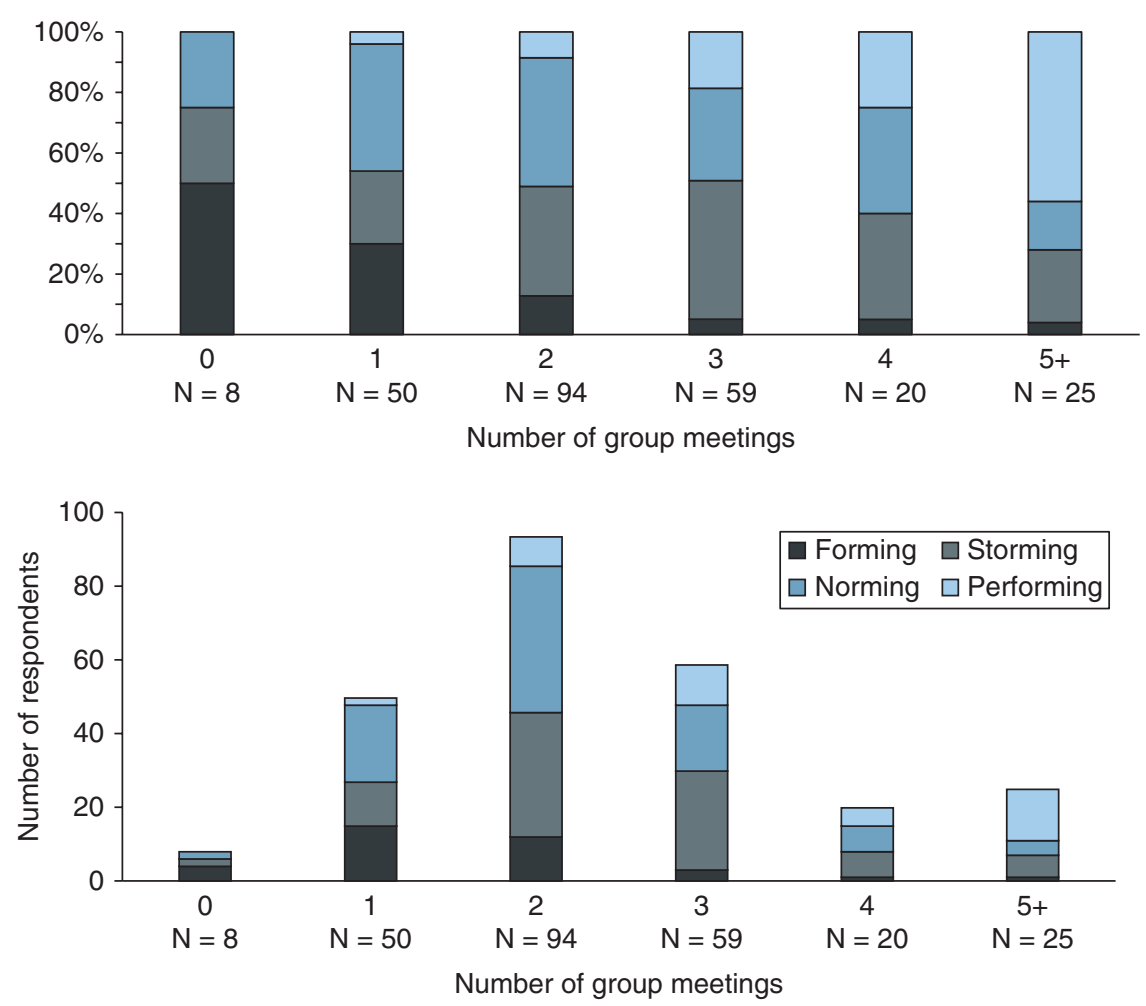

Figure 2. Group Stage versus Number of Group Meetings Reported by Students.

\section{DISCUSSION AND CONCLUSION}

Students' online work reveals that most students reported tensions within their group. Only $5 \%$ of students reported no sources of tension, while $81 \%$ of respondents reported having at least one source of tension with either an intermediate or important impact on their group, and 58\% reporting at least one source of tension which had a strong impact on their group. Ford and Morice ${ }^{5}$ report that teachers often underestimate the extent to which students experience problems in group work - it is evident from this data that teachers should be aware of the high frequency and degree of importance of the difficulties encountered by students. It further underlines the need to provide students with ideas and tools for dealing with tensions and managing conflicts in their groups. Indeed, such supports were provided to these students and it is possible that tensions may have been more pronounced without the supports.

Analysis of the on-line data also suggests a shift in students' concerns during the process of group work. Before groups were formed, concerns were primarily related to investment of group members in the task (people being late, people not investing work in the project, people "free riding" on the group), and to the interpersonal relationships in the group (concerns about some people seeking to take over the group, or about poor communication).

When students were asked again five weeks later about the sources of tension within their group, personality differences or different styles of communication remained important, as did different grade aspirations or degrees of involvement in the project (these broadly match their stated concerns at the outset of the course, before their groups were formed). However, other sources of tension were now 
also noted by quite a few students, with $37 \%$ of students seeing cultural or linguistics differences as being either an intermediate or an important source of tension in their group, and $29 \%$ citing their different disciplines as an intermediate or important source of tension. This reflects the distinctiveness of group work in a professional engineering context - that is, a context in which working across disciplinary boundaries and across cultural contexts is important. Having experience of these difficulties is valuable for students, so long as they are able to learn from them. This highlights the importance of providing guidance and advice for students and suggests a need to target resources offered to students to allow them to reflect upon and decide how to act in the context of tensions which are novel to the students.

Interestingly, students report more positive group experiences when the instructor forms the groups ${ }^{16}$ however concerns about students' intensive schedules in first year, and the mix of students from across the programs, resulted in the choice to allow students to create their own groups in this course. Finding times when the whole group can meet, identified as a key challenge by students but which often remains invisible to instructors ${ }^{5}$, was further addressed by devoting 2 hours in-class time per week during the final 4 weeks of the project for work on the project. Allocating substantial in-class time was identified as an important criteria for students feeling that they had benefited from the group work ${ }^{16}$. This likely meant that finding time to meet, found in other research on group projects to be a source of tension, was less evident here.

The course materials described the journey towards productive group work in terms of four stages: Forming, Storming, Norming and Performing. Given the relatively short project timeframe ( $\leq 3$ months), it is notable that relatively few students reported getting beyond the Norming stage (16\%). It is thus questionable that students had time to develop an understanding of how the kinds of groups they will experience in their professional life actually evolve over time. Furthermore, since the material on group process was provided in week two of the course, it is likely that students engaged with this material drawing only on their prior experiences of group work (which were notably different to their experiences in the course's group project). In response, both the timing and content of the material on group work should be reviewed to ensure that it addresses what students are ready to learn and when they are ready to learn.

In conclusion, we return to the goals of this analysis. The issue of timeframe in the group development process and that of the project remains an important consideration for providing useful resources for students around working in groups. Secondly, this data can inform the design of resources which are more responsive both to the ways students frame the problems they have encountered in group work and the nature of the problems. For example, our resources sought to present disagreement as a healthy part of working in a group but this did not reflect the real stress and frustration of students on a tight schedule and under pressure for grades. Finally, teachers must be aware of the strong impact and diverse causes of the problems faced by students when working in groups. As more engineering programs introduce projects into an already stressful first year, more energy and consideration should be put into providing appropriate and useful supports to students for learning productive group skills.

\section{REFERENCES}

[1] Crawley EF, Malmqvist J, Östlund S, Brodeur DR, Edström K. Rethinking Engineering Education, the CDIO approach. $2^{\text {nd }}$ Edition. Cham: Springer; 2014.

[2] ABET. Criteria for accrediting engineering programmes, effective for reviews during the 2014-2015 accreditation cycle. Baltimore: ABET, the Engineering Accreditation Commission; 2013.

[3] Commission des titres d'Ingénieur. Accreditation Criteria, Guidelines and Procedures. Neuilly-sur-Seine: Commission des titres d'Ingénieur; 2012.

[4] Colbeck CL, Campbell SE, Bjorklund SA. Grouping in the Dark: What College Students Learn from Group Projects. The Journal of Higher Education. 2000;71(1):60-83.

[5] Ford M, Morice J. How fair are group assignments? A survey of students and faculty and a modest proposal. Journal of Information Technology Education: Research. 2003;2(1):367-378.

[6] Cohen EG. Designing Groupwork. $2^{\text {nd }}$ Edition. New York: Teacher's College Press; 1994.

[7] Forsyth DR. Group Dynamics. 5th Edition. Belmont CA: Wadsworth Cengage Learning; 2010.

[8] Bonebright DA. 40 years of storming: a historical review of Brice Tuckman's model of small group development. Human Resource Development International. 2010;13(1):111-120.

[9] Tuckman BW. Developmental sequence in small groups. Psychological Bulletin.. 1965;65(6):384-399.

[10] Miller D. The stages of group development: A retrospective study of dynamic team processes. Canadian Journal of Administrative Sciences,. 2003;20(2):121-143.

[11] Tuckman BW, Jensen MA. Stages of small-group development revisited. Group and Organization Studies. 1977:2(4):419-427. 
Page 8 of 8

Isaac and Tormey, QScience Proceedings 2015.elc2014:19

[12] Wheelan SA, McKeage R. Developmental patterns in small and large groups. Small Group Research. 1993;24:60-83.

[13] Wheelan SA, Davidson B, Tilin F. Group Development Across Time, Reality or Illusion?. Small Group Research. 2003;34(2):223-245.

[14] Lehmann M, Christensen P, Du X, Thrane M. Problem-oriented and project-based learning as an innovative learning strategy for sustainable development in engineering education. European Journal of Engineering Education. 2008;33(3):283-295.

[15] Clark DR. Teamwork Survey, Retrieved from http://www.nwlink.com/ donclark/leader/teamsuv.html [website]. Note: Three questions dealing with the role of the team leader were omitted. 2012.

[16] Feichtner S, Davis E. Why Some Groups Fail: a Survey of Students' Experiences with Learning Groups. Journal of Management Education. 1984;9(4):58-73. 